\title{
Erkek öğretmenlerde cinsel sağlık problemleri ve ilișkili faktörlerin belirlenmesi: web tabanlı araștırma
}

\section{Sexual health problems in men teachers and determination of related factors: web-based research}

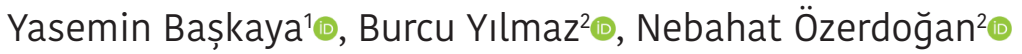

\section{öz}

AMAC,: Erkek cinsel sağlık sorunları sık rastlanan sorunlar olmalarına karşın, ne yazık ki toplumdaki algısı nedeniyle tedaviye başvuru oranı düşüktür. Ülkemizde erkek cinsel sorunlarının yaygınlığı ve ilișkili etmenlerini ele alan çalışma sayısı oldukça yetersizdir. Bu araştırmanın amacı, ilköğretim ve ortaöğretim okullarında görev yapan erkek öğretmenlerin cinsel sağlık sorunlarını ve ilişkili olabilecek faktörleri belirlemektir.

GEREÇ ve YÖNTEM: Tanımlayıcı-kesitsel olarak yapılan bu çalışma web tabanlı araştırma modelindedir. İnterneti en çok kullanan meslek gruplarından biri olan öğretmenler, yoğun ve stresli çalışma koşulları nedeniyle çalışma grubu olarak belirlenmiştir. İnternet ortamında "öğretmenlik mesleği" ile ilgili çeşitli forum veya sosyal medya gruplarına üye, mesleği öğretmenlik olan kullanıcilardan, belirlenen tarihlerde anketi cevaplayanlar örneklem grubunu olusturmustur. Online anket uygulaması 01 Temmuz 2016 - 01 Temmuz 2017 tarihleri arasında yapılmış ve uygulama süresi sonunda 143 erkek öğretmen örneklem olarak kabul edilmiştir. Veri toplamada, araştırmacı tarafından literatür doğrultusunda hazırlanan öğretmenlerin sosyo-demografik tanıtıcı özelliklerini, sağlık durumu bilgilerini ve cinsel sağlığına ilişkin sorunlarını inceleyen soru formu kullanılmıştır. Verilerin istatistiksel analizi, bilgisayar ortamında SPSS 21.0 paket programı kullanılarak yapılmıştır. Verilerin analizinde ki-kare testi, Independent Sample t test, MannWhitney U kullanılmıştır.

BULGULAR: Araştırmaya katılan öğretmenlerin yaş ortalaması 33,05 $\pm 8,63$ 'dir. Öğretmenlerin \%73,4'ünün aktif cinsel yașamı olup, \%40,6'sı yaşamının herhangi bir döneminde veya şimdi cinsel sağlık sorunu yaşadığını belirtmiştir. Prematür ejakülasyon yaşadığını belirten katılımcı oranı $\% 33,6$, cinsel istek sorunu yaşayan $\% 11,9$, erektil disfonsiyon yaşayan $\% 9,8$ 'dir. Cinsel sağlık sorunlarından prematür ejakülasyon ve cinsel istek sorunu yaşayanların stres düzeyleri bu sorunu yaşamayanlarla karşılaşııııldığında yüksek bulunmuştur. Ayrıca, spor ya da egzersiz gibi fiziksel aktivitesi olmayan ve beden kitle indeksi 25 'in üzerinde olan kişilerde prematür ejakülasyon yaşama oranı daha fazla bulunmuştur.

SONUÇ: Çalışmamızın sonuçları ülkemizde tartışılması tabu olan erkek cinsel sağlığı hakkında önemli bilgiler vermektedir. Yoğun ve stresli çalışma koşullarına sahip öğretmenlerin stres düzeyleri ile cinsel sağlık sorunları arasında ilişkinin olduğu görülmektedir. Araştırmanın sonuçları doğrultusunda erkek cinsel sağlığı konusunda farkındalığı arttırmak amacıyla sağlık eğitimlerinin planlanıp uygulanması önerilmektedir.

Anahtar Kelimeler: Cinsel sağılk, cinsel disfonksiyon, prematür ejakülasyon

\section{ABSTRACT}

OBJECTIVE: Although male sexual health dysfunctions are common problems, unfortunately the rate of admission for treatment is low due to their perception in society. The number of studies addressing the prevalence and related factors of male sexual health problems in Turkey is quite low. The aim of this study is to determine the sexual health problems of male teachers working in elementary and high schools, and related factors.

MATERIAL and METHODS: Descriptive cross-sectional study is based on a web-based research model. Teachers, who are one of the professional groups that use the internet most, have been determined as working group due to intensive and stressful working conditions. The members of various online forums or social media groups related to the teaching profession are selected as target, and the sample group consisted of those who replied to the questionnaire at the determined dates. Online survey was conducted between 01 July 2016 and 01 July 2017, and 143 male teachers were accepted as samples. In the data collection, the questionnaire which examines the sociodemographic characteristics, health status information and sexual health problems prepared by the researcher in accordance with the literature has been used. Statistical analysis of the data was done by SPSS version 21.0. Chi-square test, Independent Sample t test, Mann-Whitney U were used for data analysis.

RESULTS: The mean age of the teachers who participating in the research was $33.05 \pm 8.63$. The teachers who stated that they have active sexual life was $73.4 \% ; 40.6 \%$ of the teachers state some kind of sexual health problem at any time in their lives or now. The percentage of participants who had experienced premature ejaculation was $33.6 \%$, the sexual desire problem was $11.9 \%$, and the erectile dysfunction was $9.8 \%$. Stress levels of those experiencing premature ejaculation and sexual desire disorder were higher than those who did not. Also, the rate of premature ejaculation was found to be higher in people who did not have any physical activity (sports/exercise) and who had body mass index more than 25 .

CONCLUSION: The results of our study gives important information about male sexual health which is considered as taboo in our country. It is observed that there is a relationship between stress levels and sexual health problems of teachers with intense and stressful working conditions. It is recommended to plan and implement health education programs in order to raise awareness on male sexual health.

Keywords: Sexual health, sexual dysfunctions, premature ejaculation

${ }^{1}$ Sakarya Üniversitesi Sağlık Bilimleri Fakültesi, Ebelik Anabilim Dalı, Sakarya, Türkiye

${ }^{2}$ Eskişehir Osmangazi Üniversitesi, Sağlık Bilimleri Fakültesi, Ebelik Anabilim Dalı, Eskişehir, Türkiye

Yazışma Adresi/ Correspondence:

Dr. Yasemin Başkaya

Sakarya Üniversitesi Sağlık Bilimleri Fakültesi, Sakarya 54000 Sakarya, Türkiye

Tel. $\quad+905556080628$

E-mail: yhamlaci@sakarya.edu.tr

Gelis/ Received: $\quad$ 19.11.2018

Kabul/ Accepted: $\quad$ 08.01.2019 


\section{GíRiș}

İnsan yaşamının önemli bir parçası olan cinsellik ve cinsel sağlık, fiziksel, ruhsal, sosyal ve kültürel yönleri olan bütünsel bir kavramdır. ${ }^{[1,2]} \mathrm{Bu}$ nedenle cinsel sağlık; diabet, hipertansiyon gibi sistemik ve kronik hastalıklardan, depresyon, stres gibi psikolojik, çalısma ortamı, statü gibi sosyokültürel ve ekonomik faktörlerden etkilenmektedir. ${ }^{[3,4]}$ Oldukça sık rastlanan cinsel sağlık sorunları bireyin sağ lığının sadece fiziksel değil aynı zamanda ruhsal ve aile sağlığı ile bağlantılı sosyal boyutunu da olumsuz etkilemektedir. Sık rastlanan sorunlar olmalarına karşın, toplumda cinselliğin tabu olarak görülmesi, damgalanma, özellikle erkeklerde cinselliğe atfedilen anlamla ilişkili güç ve prestij kaybı endişesinin yaşanması nedeniyle tedaviye başvuru oranı düşük kalmaktadır. ${ }^{[4]}$

Cinsel sağlık sorunları; cinsel işlev bozukluğu ve cinsel kimlik bozukluklarını içerir. Bu sorunlardan erkeklerde yaşanan cinsel işlev bozuklukları; prematür ejakülasyon (PE), erektil disfonksiyon (ED), cinsel istek azlığı, geç boşalma ve ağrılı cinsel birleşme gibi sorunlardır. ${ }^{[2,5]}$

Uluslararası Seksüel Tip Derneğinin (ISSM) en son tanımına göre PE ejakülasyonun hemen her zaman vajinal penetrasyondan önce veya vajinal penetrasyondan sonraki bir dakika içerisinde olduğu, geciktirilemediği ve sonuçta kişilerde üzüntü, stres ve cinsel ilişkiden kaçınma gibi olumsuz düşüncelere neden olan bir erkek cinsel sağllk sorunudur. [6] Amerikan Psikiyatri Birliği'nin DSM-5 tanı kılavuzuna göre $\mathrm{ED}$; en az altı ay süreli olarak cinsel ilişkilerin tümünde cinsel etkinlik sonuçlanana kadar sertleşmeyi sağlayamama ve sürdürememe veya yetersiz sertleşmenin olmasıdır. ${ }^{[7]}$ Yaşları 40 ile 80 arasında değişen 13618 erkeğin katıldığı aralarında Türkiye'nin de olduğu 29 ülkede yapılan ve 40 yaşından sonra cinsel disfonksiyon sıklığının araştırıldığı çalışmada PE \%12,4 (Ortadoğu Bölgesi)-\%30,5 (Güneydoğu Asya) arasında görülen oranla en yaygın, ED \%12,9 (Güney Avrupa)-\%28,1 (Güneydoğu Asya) arasındaki oranla ikinci sırada görülen sorun olarak belirlenmiştir. ${ }^{[8]}$

Çalışma hayatı, modern insanın daha verimli olması ve yaşamını sürdürebilmesi için mecburen içinde olduğu, bireyler üzerinde etkisi büyük olan, fiziksel ve ruhsal sağlığını zamanla etkileyen, bir süreci kapsar. Işııhan (2004) öğretmenlik mesleğini, eğitim ortamında kişilerin etkisinde kaldıkları özgün ve yoğun stres yaratan durumlar sebebiyle, bireylerin özellikle ruhsal sağlıklarının ve buna bağlı olarak da çalışma yaşamlarının kötü yönde etkilenmesinde önemli oranda risk taşıyan bir meslek olarak yorumlamıştır. ${ }^{[9]}$ Öğretmenlerin genel olarak diğer meslek çalışanlarına göre daha fazla stres yaşama nedenleri; eğitim-öğretim hizmetlerindeki öğrenci-öğretmen ve okul-aile çatışmaları, disiplin sorunları, kalabalık sınıflar, fiziki koşullardaki yetersizlik, bürokratik işlerin çokluğu, toplumun eleştirileri, eğitim kurumları üzerindeki sosyal ve politik baskılar, ödüllendirme ve karara katılımın yetersizliği gibi sorunlardır. ${ }^{[10]}$ Araştırmalarda psikolojik stres, erkeklerde libidonun azalması, testosteronun salınımı ve sperm üretiminin baskılanmasıyla ilişkilendirilmiştir. ${ }^{[11]}$ Psikolojik stresin yarattığı bu sonuçlar erkeklerde cinsel fonksiyon bozukluğu görülme riskini artırmaktadır. Bodenmann ve ark., stres ile cinsel işlev arasındaki ilişkiyi inceleyen çalışmalarında, günlük stres faktörlerinin cinsel problemlere büyük yaşam olaylarından daha fazla neden olduğunu göstermişlerdir. ${ }^{[12]}$

Ülkemizde kadın cinsel sağlığına yönelik çalışmaların sayısı oldukça fazladır. Buna karşın erkeklerde cinsel sorunların yaygınlığı ve ilişkili olan durumları ele alan çalışma sayısı oldukça yetersizdir. Bu alandaki araştırma eksikliği bizi bu çalışmayı yapmaya yönlendirmiştir. $\mathrm{Bu}$ nedenle araştırmada, ilköğretim ve ortaöğretim okullarında görev yapan erkek öğretmenlerde cinsel sağlık sorunlarının ve ilişkili faktörlerin belirlenmesi amaçlanmıştır.

\section{GEREÇ VE YÖNTEM}

Tanımlayıcı-kesitsel olarak yapılan bu çalışma web tabanlı araştırma modelindedir. Web tabanlı araştırmalar, araştırmacıların araştırmalarını internet üzerinden yapabilmelerine olanak sağlayan bir yöntem olarak kabul edilmektedir.

Teknoloji ve interneti en çok kullanan meslek gruplarından biri olan öğretmenler, yoğun ve stresli çalışma koşulları nedeniyle çalışma grubu olarak belirlenmiştir. Bu çalışmada verilerin toplanacağı evren Türkiye'de çalışan erkek öğretmenlerin tümüdür. Ancak, evrenin tümüne ulaşmanın mümkün olmamasından dolayı internet ortamında "öğretmenlik mesleği" ile ilgili çeşitli forum veya sosyal medya gruplarına üye olan kullanıcılardan, belirlenen tarihlerde anketi cevaplayanlar örneklem grubunu oluşturmuştur. Anket online olarak bir yıl boyunca erişime açık olarak kalmıştır, bu süre boyunca araştırmacılar her ay çeşitli forum ve sosyal medya gruplarında anket linkini açıklayıcı bir bilgi ile birlikte paylaşmıştır. Online anket uygulaması 01 Temmuz 2016 - 01 Temmuz 2017 tarihleri arasında yapılmıştır, uygulama süresi sonunda anketlerin tutarlı bir şekilde doldurulup doldurulmama ve öngörülen analizlere uygunluk durumları incelenmiş ve 143 erkek öğretmen örneklem olarak kabul edilmiştir. Veri toplama süresi göz önüne alındığında örneklem sayısının bu kadar az olmasında; yapılan bu web tabanlı araştırmada kimlik bilgisi istenmemesine rağmen erkek öğretmenlerin kendi 
kimliklerinin açığa çıkacağından endişe etmiş olabilecekleri, ayrıca ülkemizde hala erkek cinsel sağlığı konuları ve sorunlarının konuşulmasının tabu olarak görülmesinin etkili olabileceği düşünülmektedir.

Veri toplama aracı olarak araştırma değişkenlerini ölçmeye yönelik ifadelerin yer aldığı anket formu kullanılmıştır. Anket formu; öğretmenlerin sosyo-demografik tanıtıcı özelliklerini, sağlık durumu bilgilerini ve cinsel sağlığına ilişkin sorunlarını inceleyen üç bölümden oluşmaktadır. Çalışmamızda cinsel sağlık sorunlarına yönelik herhangi bir ölçme aracı kullanılmamış olup, yaşanılan sorunlar katılımcıların kendi ifadesidir. Bu nedenle yaşanan sorunlar tanı yaygınlığı değil, cinsel sağlık sorunu yaşayan bireylerin yaygınlığı olarak kabul edildiği için farklı kategorilerde s1nıflandırma yapılmamıştır.

Katılımcılar tarafından anketin doldurulmasını kolaylaştırmak amaciyla internet formatında hazırlanan soru formu web sayfasına yerleştirilmiştir. Anketi bilgisayar ortamında kolayca dolduran katılımcılar, gönder tuşuna basarak cevapların SPSS formatında hazırlanmış bir veritabanında toplanmasını sağlamışlardır.

\section{Verilerin değerlendirilmesi}

Çalışma verileri SPSS 21.0 for Windows programına aktarılmış, verilerin analizinde tanımlayıcı istatistiksel analizler, Ki-kare testi, Independent Sample t test, Mann-Whitney U kullanılmıştır. Sonuçlarda anlamlılık p<0,05 düzeyinde değerlendirilmiştir.

\section{Araștırma izni ve etik yönü}

Araştırmanın uygulanabilmesi için ilk önce İç Anadolu Bölgesinde bulunan bir şehirdeki İl Milli Eğitim Müdürlüğü’nden kurum izni alınarak kapalı zarf yöntemiyle veri toplama planlanmıştır ancak ankette cinsel sağlığa yönelik sorular olduğundan dolayı mahrem konular içerdiği gerekçesiyle uygun görülmemiş ve çalışmaya izin verilmemiştir. Bu nedenle araştırmacılar çalışmayı web tabanlı yapmaya karar vermiş ve araştırmanın uygulanabilmesi için etik kurul izni Eskişehir Osmangazi Üniversitesi Girişimsel Olmayan Klinik Araştırmalar Etik Kurulundan alınmıştır (sayı: 80558721/G-211).

\section{BULGULAR}

Araştırmaya katılanların yaş ortalaması 33,05 $\pm 8,63$ 'dir. (21-57) Branş dağılımlarına bakıldığında \%15,4’ü sınıf öğretmeni, \%14’ü matematik öğretmeni, \%11,9’u sosyal bilimler öğretmenidir. Öğretmenlerin \%58'i evli, evli olanların ise \%35'inin eşi üniversite mezunudur. Öğretmenlerin \%46,2'si 0-5 yıl, \%20,3'ü 6-10 yıl mesleki kıdeme sahiptir, ayrıca \%56,6’sı gelirini gidere denk olarak görmektedir.

Katılımcılara cinsel yaşamları sorulduğunda \%73,4’ünün aktif cinsel yaşamı olup, \%42,7'sinin 1 veya daha fazla sayıda çocuğu vardır. Öğretmenlerin genel sağlık durumu ile ilgili verilere bakıldığında; \%44,8'inin beden kitle indeksi (BKİ) 25-29,9 kg/m2 aralığında yani fazla kilolu grubunda olduğu görülmüştür. Öğretmenlerin \%35,7’sinin düzenli olarak sigara kullandığı, \%28'inin günde bir fincan veya daha fazla kahve tükettiği, \%16,8'inin ise alkol kullanımlarının olduğu görülmektedir. Teknoloji kullanımlarına bakıldığında; günlük telefonla konuşma ortalamaları 35,27 dakika, bilgisayar kullanım süreleri ise ortalama 3,66 saattir.

Öğretmenlerin \%59,4’ü kendisini sağlıklı olarak görmektedir ve hissettikleri stres düzeyini 1 (en düşük) ile 10 (en yüksek) arasında puanlamaları istenilen öğretmenlerin ortalama stres düzeyleri ise 5,52'dir. Öğretmenlerin cinsel sağlık durumlarıyla ilgili bilgi Tablo 1'de verilmiştir.

Katılımcıların stres düzeyleri ile cinsel sağlık sorunu yaşama durumları karşılaştırıldığında; cinsel sağlık sorunu yaşayanların stres ortalaması, sorun yaşamayanlara göre

Tablo 1. Kathlımcıların eşleriyle olan ilişkileri ve cinsel sağlık durumları

\begin{tabular}{lcc}
\hline \multicolumn{1}{c}{ Değişkenle } & Sayı (n) & Yüzde (\%) \\
\hline Eş/Partner ile olan cinsel yaşam & 1 & 1 \\
Çok Kötü & 5 & 5 \\
Kötü & 38 & 37,6 \\
Normal & 38 & 37,6 \\
İyi & 19 & 18,8 \\
Mükemmel & & \\
Eş/Partner ile olan ilişki & - & - \\
Çok Kötü & 2 & 2 \\
Kötü & 31 & 30,7 \\
Normal & 46 & 45,5 \\
İyi & 22 & 21,8 \\
Mükemmel & & \\
Cinsel sağlık sorunları* & & \\
Sorun yaşamayan & 85 & 59,4 \\
Prematür Ejakülasyon & 48 & 33,6 \\
Cinsel istek bozukluğu & 17 & 11,9 \\
Erektil Disfonksiyon & 7 & 9,8 \\
Gecikmiş Ejakülasyon & & \\
\hline
\end{tabular}

*birden çok seçenek seçilebilmiştir. 
yüksek bulunmuştur $(\mathrm{p}<0,05)$. Cinsel sağlık sorunlarından PE'si olanların stres düzeyleri bu sorunu yaşamayanlarla karşılaştırıldığında yüksek bulunmuştur $(\mathrm{p}<0,05)$ (Tablo 2).

Cinsel sağlık sorunlarından ED ve gecikmiş ejakülasyon sorunu olanlar ile bu sorunları yaşamayanlar karşılaştırıldığında stres düzeyleri arasında fark bulunamazken ( $p>0,05)$, cinsel istek bozukluğu yaşayanlarda stres ortalaması bu sorunu yaşamayanlara göre yüksek bulunmuştur $(\mathrm{p}<0,05)$ (Tablo 3).

PE sorunu yaşayan öğretmenlerin sigara kullanma, spor yapma, kahve tüketimi ve beden kitle indeksi risk faktörlerine göre dağılımına bakıldığında; spor/egzersiz yapmayan kişilerde ve beden kitle indeksi $25^{\prime}$ in üzerinde olan kişilerde PE yaşama oranı daha fazladır $(\mathrm{p}<0,05)$. Sigara kullanımı ve kahve tüketimi ile PE arasında bir ilişki bulunamamıştır (Tablo 4).

\section{TARTIȘMA}

\section{Cinsel sağlık problemlerinin görülme sıklığı}

Amerika Birleşik Devletlerinde Laumann ve ark. tarafindan yapılan 1410 örneklemli toplum çalışmasında erkeklerin \%31'inde değişik tiplerde cinsel sağlık sorunu saptanmıştır. ${ }^{[13]}$ Farklı ülke ve yaş gruplarında yapılan 21 prevalans çalışmasının sonuçlarının değerlendirildiği Cappelleri ve Rosen’in (2005) çalışmasında erkeklerde cinsel disfonksiyon görülme sıklığının \%32-64 arasında

Tablo 2. Stres düzeyleri ile cinsel sağlık sorunu yaşama durumları

\begin{tabular}{lccccc} 
Gruplar & $n$ & Stres Ortalama Puanı \pm Ss & $t$ & $s d$ & $p$ \\
\hline Cinsel sağlık sorunu yaşamayan & 85 & $5,01 \pm 2,33$ & 3,33 & 141 & 0,001 \\
Cinsel sağlık sorunu yaşayan & 58 & $6,28 \pm 2,05$ & & 2,65 & 141 \\
Prematür Ejakülasyon yaşamayan & 95 & $5,17 \pm 2,41$ & $6,23 \pm 1,91$ & 0,009 \\
Prematür Ejakülasyon yaşayan & 48 & & & \\
\hline
\end{tabular}

Tablo 3. Stres düzeyleri ile çeşitli cinsel sağlık sorunu yaşama durumları

\begin{tabular}{lcccc}
\hline Gruplar & $n$ & Stres Ortalama Puanı $5 s$ & Mann-Witney U & $p$ \\
\hline Erektil disfonksiyon yaşamayan & 127 & $5,41 \pm 2,34$ & 640,5 \\
Erektil disfonksiyon yaşayan & 14 & $6,57 \pm 1,78$ & 0,084 \\
Cinsel istek bozukluğu yaşamayan & 126 & $5,34 \pm 2,28$ & 670 \\
Cinsel istek bozukluğu yaşayan & 17 & $6,88 \pm 2,02$ & 0,012 \\
Gecikmiş Ejakülasyon yaşamayan & 136 & $5,54 \pm 2,26$ & 474,5 \\
Gecikmiş Ejakülasyon yaşayan & 7 & $5,29 \pm 3,2$ & 0,989 \\
\hline
\end{tabular}

Tablo 4. Prematür ejakülasyon sorunu yaşayan erkek öğretmenlerin bazı risk faktörlerine göre dağılımı

\begin{tabular}{|c|c|c|c|c|c|}
\hline \multicolumn{2}{|c|}{ Prematür ejakülasyon sorunu yaşama durumu } & \multirow{2}{*}{$\frac{\text { Sorun Yaşamayan (\%) }}{46(68,7)}$} & \multirow{2}{*}{$\frac{\text { Sorun Yaşayan (\%) }}{21(31,3)}$} & \multirow[t]{2}{*}{$x^{2}$} & \multirow[t]{2}{*}{$p$} \\
\hline \multirow{3}{*}{ Sigara kullanma } & Hiç kullanmayan & & & & \\
\hline & Bırakmış & $15(60)$ & $10(40)$ & \multirow[t]{2}{*}{0,614} & \multirow[t]{2}{*}{0,736} \\
\hline & Hala kullanan & $34(66,7)$ & $17(33,3)$ & & \\
\hline \multirow{3}{*}{ Spor/Egzersiz yapma } & Spor/Egzersiz yapmayan & $49(57,6)$ & $36(42,4)$ & \multirow{3}{*}{7,95} & \multirow{3}{*}{0,019} \\
\hline & Haftada 1-3 saat yapan & $30(76,9)$ & $9(23,1)$ & & \\
\hline & Haftada 3 saatten fazla yapan & $16(84,2)$ & $3(15,8)$ & & \\
\hline \multirow{3}{*}{ Kahve tüketimi } & Tüketmeyen & $18(72)$ & $7(28)$ & \multirow{3}{*}{4,49} & \multirow{3}{*}{0,106} \\
\hline & Nadiren tüketen & $46(59)$ & $32(41)$ & & \\
\hline & $\begin{array}{l}\text { Günde bir fincan ve ya daha fazla } \\
\text { tüketen }\end{array}$ & $31(77,5)$ & $9(22,5)$ & & \\
\hline \multirow{2}{*}{ Bкi } & $25<$ & $54(76,1)$ & $17(23,9)$ & \multirow{2}{*}{5,85} & \multirow{2}{*}{0,016} \\
\hline & $25>$ & $41(56,9)$ & $31(43,1)$ & & \\
\hline
\end{tabular}

*satır yüzdeleri alınmıştır 
değiştiği bildirilmiştir. Görülme oranı yaş ilerledikçe artı̧̧ göstermektedir. ${ }^{[14]}$ Bizim çalışmamızda ise; katılımcıların \%40,6'sı literatürle uyumlu olarak yaşamlarının herhangi bir döneminde veya şimdi cinsel sağlık sorunu yaşadığını belirtmiştir. Çalışmamızda herhangi bir ölçme aracı kullanılmadığı ve katılımcının kendi ifadesine dayalı olduğu için saptanan sonuç cinsel sağlık sorunu tanı yaygınlığı değil, cinsel sağlık sorunu yaşayan bireylerin yaygınlığı olarak değerlendirilmelidir.

PE; literatürde \%14,5-40'a kadar çıkan prevalans oranları ile erkekte tüm yaş grupları için en sık görülen cinsel işlev bozukluğudur. ${ }^{[15]}$ Porst ve ark.'nın 3 ülkeden $18-70$ yaş arası 12,133 erkeği dahil ettikleri Premature Ejaculation Prevalence and Attitude (PEPA) çalısmasına göre, PE prevalansı ABD'de \%22,7 Almanya ve İtalya'da \%20 oranındadır. ${ }^{[16]}$ Türkiye dahil 29 ülkede yapılan, $40-80$ yaş arasındaki erkeklerin değerlendirildiği Cinsel Tutum ve Davranışların Küresel İncelenmesi çalışmasında Latin Amerika'da \%28,3, Orta Doğu'da \%12,4, Güneydoğu Asya'da \%30,4, Avrupa'da ise \%21 oranında PE saptanmıştır. Ortadoğu bölgesi dışındaki tüm bölgelerde cinsel fonksiyon bozuklukları içerisinde PE ilk sırada tespit edilmiştir. ${ }^{[8]}$ Ülkemizde Balcı ve ark.'nın (2012) yapmış olduğu, 1412 sağlıklı erkeğin dahil edildiği çalışmada PE prevalansı \%25,7 olarak bulunmuştur. ${ }^{[17]}$ Bizim çalışmamızda ise PE sorunu yaşadığını belirten katılımcı oranı \%33,6'dır ve literatürle benzerlik göstermektedir.

Toplum temelli çalışmalarda cinsel istek bozukluğu erkeklerin \%0-15'inde bildirilmiştir. ${ }^{[18]}$ Yirmi dokuz ülkenin dahil edildiği bir çalışmada geçtiğimiz yıl en az bir kez cinsel ilişkiye girmiş olan 11,205 erkek arasında cinsel isteksizliğin yaygınlığı, Güney Avrupa'da \%13, Orta Doğu'da ise $\% 21,6$ olarak bulunurken ${ }^{[8]}, 40-80$ yaşları arasındaki 742 Amerikalı erkekle yapılan başka bir çalışmada ise, erkeklerin $\% 18,1$ 'inde cinsel istek bozukluğu belirlenmiştir. ${ }^{[19]}$ Bizim çalışmamızda ise cinsel istek bozukluğu oranı \%11,9 olarak bulunmuştur. Sonuç literatürle benzerlik göstermesine rağmen, yaş, ülke ve kültür farklılıkları, katılımcıların eğitim düzeyi, anksiyete ve stres düzeyleri, farklı sorgulama formlarının kullanılması ve değerlendirme yöntemlerinin farklılıkları gibi nedenlerin çalışmalardaki sonuç farklılıklarıyla ilişkili olduğunu düşündürmüştür.

$\mathrm{ED}$, başarılı cinsel ilişki için yeterli ereksiyonun sağlanamamasıdır. Epidemiyolojik çalışmalar erkeklerin yaklaşık \%5-20'sinin orta ve şiddetli ED'ye sahip olduklarını göstermektedir. ${ }^{[20]}$ Belçika, Almanya, İsveç, Fransa, İtalya ve İspanya’yı kapsayan bir çalışmada ED sıklığı \%18 olarak bulunmuştur. ${ }^{[21]}$ Ülkemizde Akkuş ve ark.'nın (2002), 40-70 yaş grubundaki 1982 erkeği kapsayan prevalans çalışmasında ED'nin derecelere göre \%33,2 hafif, \%27,5 orta ve \% 8,5 tam olarak saptandığı belirtilmiştir. ${ }^{[22]}$ Erkek Sağlığı Bilinçlendirme Projesi'nde ortalama yaşı 48 olan 11586 erkeğin $\% 5$ şiddetli, \%9 orta derecede ED bulunmuştur, Balcı ve ark.'nın çalışmasında ise erkeklerin $\% 2,5$ 'inde orta, \%0,7'sinde şiddetli ED saptanmıştır. ${ }^{[17]}$ Bizim çalışmamızda ise erkeklerin \%9,8'i ED yaşadığını belirtmiştir. Sonuçlar literatür ile benzerlik göstermekle birlikte, çalışmamızda bir sorgulama formunun kullanılmaması nedeniyle ED derecelendirmesi yapılamamışırı.

\section{Risk faktörleri}

Cinsellik içgüdüsel bir durum olmasına rağmen; kronik hastalık varlığı, depresyon ve stres, egzersiz alışkanlığı, sigara ve kahve tüketim alışkanlığı gibi faktörlerden etkilenmektedir. Sorumluluk, disiplin sorunları, kişiler arası çatışma, fiziki mekan ve çevre şartları, yoğun iş yükü gibi stres etmenleri öğretmenlerin cinsel arzu ya da performansını azaltabilir, seksüel disfonksiyona neden olabilir. [23,24] Porst ve ark.'nın yapmış olduğu bir çalışmada PE'li erkeklerin PE'li olmayan erkeklere kıyasla aşırı stres, depresyon ve anksiyete gibi psikolojik sıkıntıları bildirmeleri daha yüksek bulunmuştur. ${ }^{[16]}$ Bizim çalışmamızda da cinsel disfonksiyon yaşayanların (PE ve cinsel istek bozukluğu) stres düzeyleri sorun yaşamayanlara göre daha yüksek bulunmuştur $(6,28$ vs 5,01$)$. PE ve cinsel isteksizlik problemi olanlar olmayanlara göre daha yüksek stres düzeyi bildirmişledir.

Son yayınlanan bazı kanıtlar obezite ve egzersiz yapmak ile ED arasında bir ilişki olduğunu düşündürmesine rağmen, BKİ ve PE arasındaki ilişki çok az incelenmiştir. ${ }^{[20,25]}$ Esposito ve ark.'nın yaptığı çalışmada, hayat tarzı değişiklikleri, düzenli egzersiz ve kilo verme sonrasında obez hastaların \%33'ünün normal cinsel aktivitelerini yeniden kazandıkları bildirilmiştir. ${ }^{[26]}$ Gao ve ark.'nın 3016 kişiyle yapmış olduğu çalışmada PE şikayeti olan hastalar, şikayeti olmayan hastalara göre daha yüksek beden kitle indeksine sahip bulunmuştur. ${ }^{[27]}$ Bizim çalışmamızda da spor yapmayanlarda ve BKİ 25'in üzerinde olanlarda PE sorunu daha çok görülmüştür. Sedanter yaşamın ve BKİ'inin cinsel sağlık sorunları açısından risk faktörü olup olmadığını değerlendirebilmek için örneklem grubu geniş olan daha fazla çalışma yapılmasına ihtiyaç vardır.

\section{SONUÇ}

Kişi üzerinde büyük etkisi olan ancak toplumsal ve sosyal faktörlerin etkisi ile mahrem kabul edilen cinsellik, sağlık profesyonelleri tarafindan da çok fazla araştırılmamakta ve ele alınmamaktadır. Çalışmamızın sonuçları ülkemizdeki 
erkek öğretmenlerin cinsel sağlıkları hakkında önemli bilgiler vermektedir. Yoğun ve stresli çalışma koşullarına sahip öğretmenlerin stres düzeyleri ile cinsel sağlık sorunları arasında ilişkinin olduğu görülmektedir. Üniversite mezunu ve bilinçli olarak düşündüğümüz kesimlerin bile erkek cinsel sağlığı konusunda yeterli farkındalığı olmadığı görülmekte, bu yüzden doğru bilgilendirmenin ve yönlendirmenin yapılması gerekmektedir. Erkek üreme ve cinsel sağlığ 1 konusunda geniş örneklem içeren çalışmaların yapılması ve toplumun bu konuda bilinçlendirilmesi gerekmektedir.

\section{Hakem Değerlendirmesi}

Dış bağımsız

Çıkar Çatışması

Yazarlar çıkar ilişkisi olmadığını beyan etmişlerdir.

\section{Finansal Destek}

Herhangi bir mali destek alınmamıştır.

\section{Peer-review}

Externally peer-reviewed.

Conflict of Interest

No conflict of interest was declared by the authors.

\section{Financial Disclosure}

No financial disclosure was received.

\section{KAYNAKLAR}

1. Taylor B, Davis S. Using the extended PLISSIT model to address sexual healthcare needs. Nurs Stand 2006;21:35-41. [CrossRef]

2. Uslu E, İnfal S, Ulusoy MN. Cinsel Sorunların Çözümünde PLISSIT Modelinin Etkisi. Psikiyatride Güncel Yaklaşımlar 2016;8:52-63. [CrossRef]

3. Doğan S. Cinsel işlev bozuklukları, depresyon ve antidepresanlar. J Mood Disord 2011;1:81-6. [CrossRef]

4. İncesu C. Cinsel işlevler ve cinsel işlev bozuklukları. Klinik Psikiyatri Derg 2004;7:3-13.

5. World Health Organization, Department of Reproductive Health and Research. Defining sexual health: report of a technical consultation on sexual health, 28-31 January 2002, Geneva: World Health Organization; 2006.

6. McMahon CG, Althof S, Waldinger MD, Porst H, Dean J, Sharlip I, et al. An evidence-based definition of lifelong premature ejaculation: Report of the International Society for Sexual Medicine Ad Hoc Committee for the Definition of Premature Ejaculation. BJU Int 2008;102:338-50. [CrossRef]

7. Kulacaoğlu F. Psikojenik nedenli erektil disfonksiyon. Androloji Bült 2016;18):230-2.

8. Laumann EO, Nicolosi A, Glasser DB, Paik A, Gingell C, Moreira E, Wang T; GSSAB Investigators' Group.. Sexual problems among women and men aged 40-80 y: prevalence and correlates identified in the Global Study of Sexual Attitudes and Behaviors. Int J Impot Res 2005;17:39. [CrossRef]

9. Işıkhan V. Çalışma Hayatında Stres ve Başa Çıkma Yolları. Ankara: Sandal Yayınları; 2004.

10. Cemaloğlu N, Kayabaşı Y. Öğretmenlerin tükenmişlik düzeyi ile sınıf yönetiminde kullandıkları disiplin modelleri arasındaki ilişki. Gazi Üniversitesi Gazi Eğitim Fakültesi Derg 2014;27:123-55.
11. Hamilton LD, Julian AM. The relationship between daily hassles and sexual function in men and women. J Sex Marital Ther 2014;40:379-95. [CrossRef]

12. Bodenmann G, Atkins DC, Schär M, Poffet V. The association between daily stress and sexual activity. J Fam Psychol 2010;24:2719. [CrossRef]

13. Laumann EO, Paik A, Rosen RC. Sexual dysfunction in the United States: prevalence and predictors. JAMA 1999;281:53744. [CrossRef]

14. Cappelleri JC, Rosen RC. The Sexual Health Inventory for Men (SHIM): a 5-year review of research and clinical experience. Int J Impot Res 2005;17:307-19. [CrossRef]

15. Gunes M, Akçalı H, Dede O, Okan A, Bulut M, Demir S, et al. Prematür Ejakülasyon Olgularında Cinsel Mitlere İnanma Düzeyi. Dicle Med J 2016;43:319-28.

16. Porst H, Montorsi F, Rosen RC, Gaynor L, Grupe S, Alexander J. The Premature Ejaculation Prevalence and Attitudes (PEPA) survey: prevalence, comorbidities, and professional help-seeking. Eur Urol 2007;51:816-24. [CrossRef]

17. Balcı M, Aslan Y, Aydın A, Kayalı M, Tuncel A, Atan A. Türk erkeklerinde cinsel fonksiyon bozukluğu taraması: anket çalışması. Ortadoğu Tıp Derg 2012 4:108-13.

18. Meuleman EJH, Van Lankveld JJDM. Hypoactive sexual desire disorder: an underestimated condition in men. BJU Int 2005;95:291-6. [CrossRef]

19. Laumann EO, Glasser DB, Neves RCS, Moreira ED Jr. A populationbased survey of sexual activity, sexual problems and associated helpseeking behavior patterns in mature adults in the United States of America. Int J Impot Res 2009;21:171-8. [CrossRef]

20. Hatzimouratidis K, Amar E, Eardley I, Giuliano F, Hatzichristou D, Montorsi F, et al. Guidelines on male sexual dysfunction: erectile dysfunction and premature ejaculation. Eur Urol 2010;57:804-14. [CrossRef]

21. Moreira ED, Glasser DB, Nicolosi A, Duarte FG, Gingell C; GSSAB Investigators' Group. Sexual problems and help-seeking behaviour in adults in the United Kingdom and continental Europe. BJU Int 2008;101:1005-11. [CrossRef]

22. Akkus E, Kadioglu A, Esen A, Doran S, Ergen A, Anafarta K, Hattat H. Prevalence and correlates of erectile dysfunction in Turkey: a population-based study. Eur Urol 2002;41:298-304. [CrossRef]

23. McCabe M, Althof SE, Assalian P, Chevret-Measson M, Leiblum SR, Simonelli C, Wylie K. Psychological and interpersonal dimensions of sexual function and dysfunction. J Sex Med 2010;7:327-36. [CrossRef]

24. Özkan Z, Beji NK. Psikolojik ve kişilerarası etmenlerin cinsel fonksiyon üzerine etkileri. Androloji Bült 2014;16:203-8.

25. Tuncel A, Güzel Ö, Atan A. Erektil disfonksiyonda rol oynayan risk faktörlerini belirleme. Androloji Bült 2013;15:158-63.

26. Esposito K, Giugliano F, Di Palo C, Giugliano G, Marfella $R$, D'Andrea $F$, et al. Effect of lifestyle changes on erectile dysfunction in obese men: a randomized controlled trial. JAMA 2004;291:2978-84. [CrossRef]

27. Gao J, Zhang X, Su P, Liu J, Xia L, Yang J, et al. Prevalence and Factors Associated with the Complaint of Premature Ejaculation and the Four Premature Ejaculation Syndromes: A Large Observational Study in China. J Sex Med 2013;10:1874-81. [CrossRef] 